\title{
Anatomy and Clinical Importance of the Extracranial Clivus and Surrounding Structures
}

\author{
Anatomía e Importancia Clínica del Clivus Extracraneal y las Estructuras Circundantes
}

Huseyin Erdem ${ }^{1}$ Emine Dondu Kizilkanat ${ }^{1}$; Neslihan Boyan ${ }^{1}$; Roger Soames ${ }^{2} \&$ Ozkan Oguz $^{1}$

ERDEM, H.; KIZILKANAT, E. D.; BOYAN, N.; SOAMES, R. \& OGUZ, O. Anatomy and clinical Importance of the extracranial clivus and surrounding structures. Int. J. Morphol., 36(2):557-562, 2018.

SUMMARY: The aim of this study was to reveal the clinical importance of measurements taken from the pharyngeal tubercle (PT) to various anatomical structures around the extracranial clivus. Twenty-six adult dry Anatolian skulls were examined. The extracranial clivus and PT were used as landmarks from which various distances were measured using a digital caliper accurate to $0.01 \mathrm{~mm}$. The following mean distances from the PT were observed; foramen lacerum (FL) (L: $17.15 \mathrm{~mm}, \mathrm{R}: 17.4 \mathrm{~mm})$; medial external margin of the carotid canal (CC) (L: $26.7 \mathrm{~mm}, \mathrm{R}: 27.5 \mathrm{~mm}$ ); anterior tip of occipital condyle (OC) (L: $16.4 \mathrm{~mm}, \mathrm{R}: 16.3 \mathrm{~mm}$ ); anterior margin of foramen magnum (FM) (10.8 mm); foramen ovale (FO) (L: $25.9 \mathrm{~mm}, \mathrm{R}: 29.1)$; medial margin of the jugular fossa (JF) (L: 25.4 mm, R: $25.7 \mathrm{~mm}$ ); medial external margin of the hypoglossal canal (HC) (L: $20.0 \mathrm{~mm}, \mathrm{R}: 19.9 \mathrm{~mm})$. Mean bilateral distances were: LFO-RFO: $45.34 \mathrm{~mm}$; LFL-RFL: $20.1 \mathrm{~mm}$; LCC-RCC: $52.1 \mathrm{~mm}$; LOC-ROC: $17.6 \mathrm{~mm}$; LJF-RJF: $45.2 \mathrm{~mm}$; LHC-RHC: $33.5 \mathrm{~mm}$. The following mean distances were observed from the FM: FM-OC (L: $8.3 \mathrm{~mm}$, R: $9.3 \mathrm{~mm}$ ); FM-HC (L: $17.8 \mathrm{~mm}$, R: $17.4 \mathrm{~mm}$ ). Also the mean distance of OC-HC were observed (L: $11.7 \mathrm{~mm}, \mathrm{R}: 11.4 \mathrm{~mm}$ ). Present measurements suggest that the PT can be used as an anatomical landmark during surgery involving clival pathology. However, the anatomy and variations of the extracranial clivus and surrounding structures must be taken into consideration.

KEY WORDS: Extracranial clivus; Middle skull base; Pharyngeal tubercle; Skull base.

\section{INTRODUCTION}

The management of the skullbase lesions espically involving the clivus has challenged neurosurgeons for several dacades (Jackson, 1981). Various neurovascular structures settled and passing through in this complex anatomical area, are potential life-threatening components for hemorrhage and infections during or after the surgery (Patel et al., 2016). The technological advancement on radiodiagnostic, anesthesia, and microsurgery equipped the specialists to interfere lesions on the skull base (Wang et al., 2016). Several approach techniques have been used for over a century. The high mortality risk associated with transcranial approaches has made the transsphenoidal approach an ineluctable alternative technique (Patel et al.). The transsphenoidal approach to the midline of the skullbase was described in late 1890s; however it did not become popular among neurosurgeons until the 1960s because of insufficient visualation, and also they were skilled in transcranial approaches (Liu et al., 2001). Following the invention and further development of the rod-lens system several surgical departments, including neurosurgery, adopted endoscopy
(Doglietto et al., 2005). Nowadays the undeniable contribution of endoscopic endonasal surgery of the skull base offers safe and effective intervention for cranial fossa pathologies. In this respect the precise morphometry of the skull base must be assessed and evaluated to enable improvements in, and the facilitation of neurosurgical operations and surgical approaches employed (Kizilkanat et al., 2006).

The skull base is a combination of several bones surrounded by numerous vital neurovascular structures (Patel et al.). Its complex anatomy requires detailed knowledge of the topography and bony landmarks. The topography of the region has been well established by anatomists and surgeons (Jackson; Patel et al.); however a lack of knowledge regarding the bony landmarks can endanger surgical approach techniques (Jackson). The clivus, an important bony component of the skull base, is a combination of the corpus ossis sphenoidalis and basal part of the occipital bone: it is pitched at $45^{\circ}$ to the vertical (Ji et al., 2012, 2015).

\footnotetext{
${ }^{1}$ Department of Anatomy, Faculty of Medicine, Cukurova University, Balcali, Adana, 01330, Turkey.

${ }^{2}$ Centre for Anatomy and Human Identification, School of Science and Engineering, University of Dundee, Dundee, UK..
} 
Based on an endoscopic endonasal approach the skull base consists of four regions, these being the anterior midline skull base, middle skull base, posterior midline skull base, and parasellar region (Solari et al., 2014). Within each region are substantial important structures which must be avoided to prevent damage during surgery. The posterior midline skull base is exposed by an endoscopic endonasal transclival approach: the clival region to the craniovertebral joint complex (CJC) can be visualised using this approach (Solari et al.).

Skull base pathologies adversely affect the quality of life and can be potentially life-threatening abnormalities (Ji et al., 2012). Inflammatory lesions, tumors, traumatic lesions, developmental disorders and deformity can result in partial or complete disruption of this important area (Ji et al., 2012). For example, clival chordomas account for 0.15-1 \% of all intracranial tumors (Erdem et al., 2003; Jian et al., 2011), there location varying depending on whether they are at the upper clival (basisphenoid) or lower clival (basiocciput) region (Stippler et al., 2009). Upper clival lesions tends to affect the pituitary gland, hypothalamus, and upper cranial nerves, while the lower clival lesions primarily affect the lower cranial nerves. If the size of the mass increases it can compress the brainstem and cause various neurological symptoms (Berson et al., 1988; Sen et al., 1989; Kondziolka et al., 1991; Stippler et al.). A number of surgical approaches, both invasive and minimally invasive, are curently used in tumor resection (Choi et al., 2010).

The CJC provides a safe route to past the spinal cord and many important and vital neurovascular structures (Gholve et al., 2007; Yin et al., 2013). Yet, in spite of its well-preserved morphology its stability is vulnerable due to multiple pathologies, such as tumors, injury, inflammation and deformity (Shin et al., 2006; Ji et al., 2012, 2015, 2016a,b), which can lead to pressure on the spinal cord and neurovascular structures (Shin et al.; Ji et al., 2016). CJC fixation methods can be divided into anterior, posterior and combined approaches. Occipitocervical fixation is commonly being used as a posterior approach (Shin et al.; Ozer et al., 2011), while more recently the clivus plate fixation method as an anterior approach has been reported (Ji et al., 2016).

The intracranial part of the clivus is surrounded by the dura and is also close to the basal artery, pons, medulla oblangata and V-XII cranial nerves (Cavallo et al., 2007; Ji et al., 2016). Extracranically the pharyngeal tubercle could be a safe landmark for the disscetion of soft tissues to exposure the clivus (Ji et al., 2012). It is for this reason that the pharyngeal tubercle is considered as a potential landmark in this study. To advance surgical techniques and facilitate safe surgical approaches to the clivus a detailed morphometric analysis of the skull base needs to be undertaken and evaluated. Consequently, the distances between the pharyngeal tubercle and various foramina transmitting cranial nerves and vessels, as well as some bony components, around the clivus have been measured, assessed and evaluated. Measurements taken from dry skulls are more sensitive than the measurements taken from CT and MRI.

\section{MATERIAL AND METHOD}

Twenty-six adult dry Anatolian skulls each with a well preserved extracranial clivus region and surrounding structures provided from the Department of Anatomy, Faculty of Medicine, Cukurova University were examined: the age and sex of the specimens were unknown. All measurements were taken using digital calipers accurate to $0.01 \mathrm{~mm}$.

The distances between the pharyngeal tubercle (PT) and the following bony landmarks were measured (Fig. 1A, $\mathrm{B})$ : foramen ovale (FO); foramen lacerum (FL); anterior tip of the occipital condyle (OC); medial external margin of the carotid canal (CC); medial margin of the jugular fossa(JF); medial external margin of the hypoglossal canal (HC); and anterior margin of the foramen magnum (FM). The distances between left and right structures above were also measured (Fig. 1C): foramen ovale (LFO-RFO); foramen lacerum (LFL-RFL); anterior tip of occipital condyle (LOC-ROC); medial external margin of the carotid canal (LCC-RCC); medial margin of jugular fossa (LJF-RJF); medial external margin of the hypoglossal canal (LHC-RHC).

In addition, the following distances which are important in surgical approaches were also measured (Fig. 1D): from the anterior margin of the foramen magnum to the tip of occipital condyle (FM-OC); from anterior margin of the foramen magnum to the medial external margin of the hypoglossal canal (FM-HC); from anterior margin of the foramen magnum to the pharyngeal tubercle (FM-PT); from the anterior tip of the occipital condyle to medial external margin of the hypoglossal canal (OC-HC).

\section{RESULTS}

The means, standard deviations and ranges of distances from the pharyngeal tubercle to each related structures, together with the distances from anterior margin of foramen magnum to the tip of the occipital condyle (FM- 

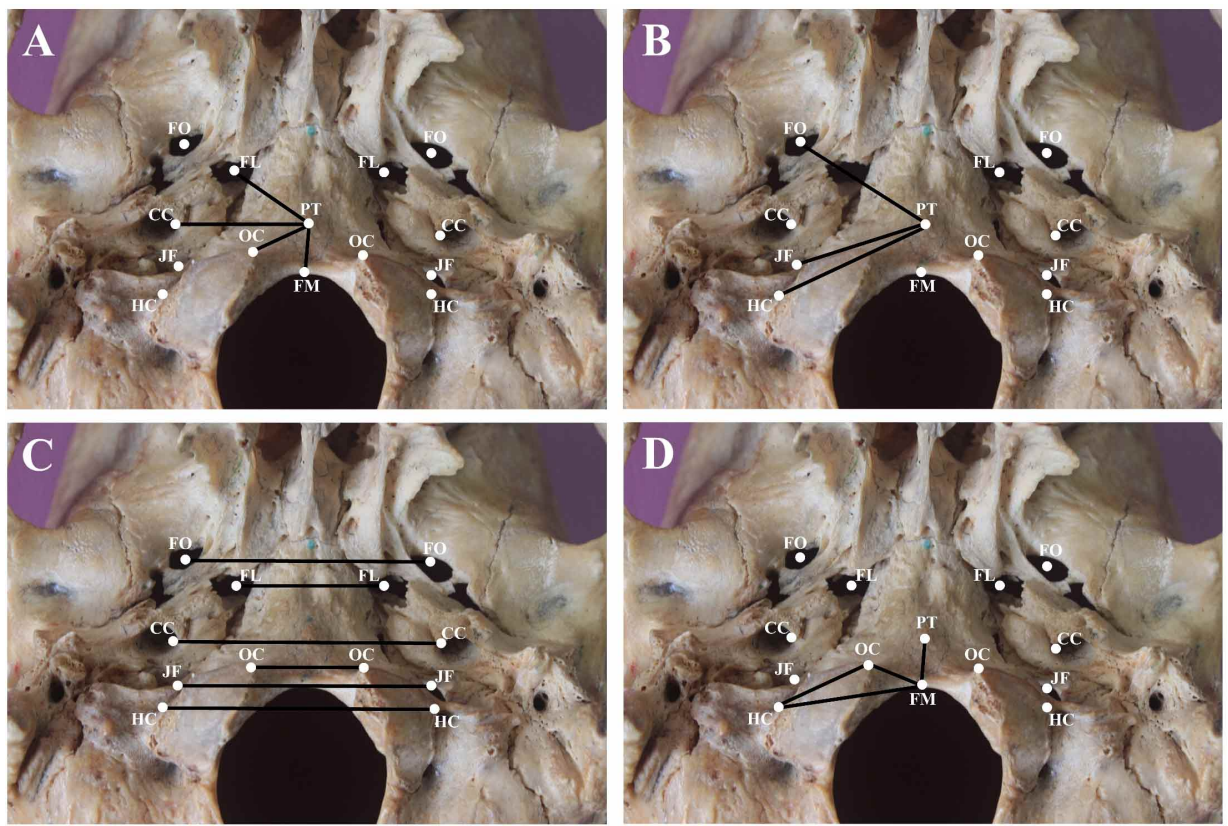

Fig. 1. A: Distance from pharyngeal tubercle (PT) to the: foramen lacerum (FL); medial external margin of the carotid canal (CC); anterior tip of the occipital condyle (OC); anterior margin of the foramen magnum (FM). B: Distance from pharyngeal tubercle (PT) to the: foramen ovale (FO); medial margin of jugular fossa (JF); medial external margin of the hypoglossal canal (HC). C: Bilateral distances (left tp right). D: Distance from the anteriror margin of the foramen magnum to the: pharyngeal tubercle (FM-PT); tip of the occipital condyle (FM-OC); medial external margin of the hypoglossal canal (HC). Distance from the anterior tip of the occipital condyle to medial external margin of the hypoglossal canal (OC-HC).
Table I. The mean, standard deviation and range of the distances $(\mathrm{mm})$ between the pharyngeal tubercle and foramen ovale (PT-FO), foramen lacerum (PT-FL), occipital condyle (PT-OC), carotid canal (PT-CC), jugular foramen (PT-JF) and hypoglossal canal (PT-HC); and between the foramen magnum and occipital condyle (FM-OC) and hypoglossal canal (FM-HC).

\begin{tabular}{ccccc}
\hline Parameters & \multicolumn{2}{c}{ Left } & \multicolumn{2}{c}{ Right } \\
& Range (n) & Mean (SD) & Range (n) & Mean (SD) \\
\hline PT - FO & $23.26-33.01(25)$ & $28.9 \pm 2.19$ & $23.71-34.42(24)$ & $29.1 \pm 2.11$ \\
PT - FL & $12.51-22.74(25)$ & $17.1 \pm 2.74$ & $12.91-23,67(25)$ & $17.4 \pm 2.80$ \\
PT - OC & $12.96-19.35(26)$ & $16.4 \pm 1.59$ & $12.94-19.76(26)$ & $16.3 \pm 1.79$ \\
PT - CC & $22.14-32.08(24)$ & $26.7 \pm 2.00$ & $21.64-31.42(24)$ & $27.5 \pm 2.22$ \\
PT - JF & $22.41-30.78(26)$ & $25.4 \pm 2.04$ & $22.32-30.48(26)$ & $25.7 \pm 2.00$ \\
PT - HC & $17.18-27.46(26)$ & $20.1 \pm 1.88$ & $17.12-28.75(26)$ & $19.9 \pm 2.30$ \\
FM - OC & $4.7-10.83(26)$ & $8.3 \pm 1.71$ & $5.77-11,14(26)$ & $9.3 \pm 1.38$ \\
FM - HC & $14.38-20.03(26)$ & $17.8 \pm 1.29$ & $14.92-19.48(26)$ & $17.4 \pm 1.44$ \\
OC - HC & $9.67-13.85(26)$ & $11.7 \pm 1.17$ & $8.45-14.54(26)$ & $11.4 \pm 1.43$ \\
\hline
\end{tabular}

OC), and medial external margin of the hypoglossal canal (FM-HC), the anterior tip of occipital condyle to medial external margin of the hypoglossal canal (OC$\mathrm{HC}$ ) are given in Table I. No significant differences $(\mathrm{P}<0.05)$ were observed between the left and right side measurements. The bilateral distances between related structures and the distance between the pharyngeal tubercle and anterior margin of foramen magnum (PT-FM) are presented in Table II.

\begin{tabular}{lcc}
\hline Parameters & Range (n) & Mean (SD) \\
\hline LFO - RFO & $40.21-50.04(24)$ & $45.4 \pm 3.14$ \\
LFL - RFL & $16.97-24.37(25)$ & $20.1 \pm 1.78$ \\
LCC - RCC & $43.94-57.76(22)$ & $52.1 \pm 4.16$ \\
LOC - ROC & $10.85-20.74(26)$ & $17.6 \pm 2.48$ \\
LJF - RJF & $40.29-53.38(26)$ & $45.2 \pm 3.74$ \\
LHC - RHC & $28.36-36.68(26)$ & $33.3 \pm 1.85$ \\
PT - FM & $6.97-18.78(26)$ & $10.8 \pm 2.15$ \\
\hline
\end{tabular}

Table II. The mean, standard deviation and range of the ach bilateral distances $(\mathrm{mm})$ between the foramen ovale (LFO-RFO), foramen lacerum (LFL-RFL), carotid canal (LCCRCC), occipital condyle (LOC-ROC), jugular foramen (LJF-RJF) and hypoglossal canal (LHC-RHC); and between the pharyngeal tubercle and foramen magnum (PT - FM). 


\section{DISCUSSION}

The skull base separates the cranium from the nasal cavity and pharynx and extends between the anterior and posterior limits of the cranial fossa. Several cranial nerves and vascular structures have a significant relationship with the skull base, cerebrum, cerebellum and brainstem. Resection of many lesions in this area are particularly challenging due to the difficulty in accessing them (Patel et $a l$.). By exposing the posterior skull base via an endoscopic endonasal transclival approach the clivus and surrounding neurovascular structures and bony components are visible. The anatomical structures can be used as limits during surgical access. Solari et al. have clearly expressed the limitations and advances of endoscopic endonasal routes, stating that the ascending part of the carotid arteries constitute the lateral border of the clivus during the endoscopic approach, with the lateral border of lower third of the clivus being limited by the foramen lacerum; however useful measurements were not provided in their study. It is clear that a knowledge of the relationships of surrounding clival structures is important in neurosurgery: the current study addresses this by providing such measurements. In the current study the mean distance between the medial external margins of the left an right carotid canals is $52.1 \mathrm{~mm}$, while the mean distance between the left and right foramen lacerum is $20.1 \mathrm{~mm}$.

The stability of the CJC is affected by several lesions: to restore stability plates and screws between the clivus and cervical vertebrae are undertaken. However, the many neurovascular structures in the region, as well as the anatomy of the clivus, makes surgery extremely difficult. Ji et al. (2012) studied both dry bones and 2D CT scans of patient's CJC to determine the entry point, trajectory and optimal length of clivus screws. Their findings provide useful information for surgical approaches and appropriate instrument selection. Ji et al. (2012) observed the distance between the foramen magnum and projection of the anterior point of the $\mathrm{C} 3$ superior articulation facing the clivus to be $10.98 \mathrm{~mm}$ in 2D CT, which was an approximate value of the distance between PT and FM $(12.76 \mathrm{~mm})$ in dry bones. The observations in the current study are similar to those of Ji et al. (2012) on 2D CT (PT-FM: $10.8 \mathrm{~mm}$ ).

Recently published studies have shown that enhanced endoscopic instruments provide minimally invasive endoscopic endonasal transsphenoidal approaches through the sellar, suprasellar, parasellar and retroclival area (Sen et al., 1989; Cavallo et al.; Stippler et al.; Choi et al.). The lower third of the clivus and anterior third of the occipital condyles is removed for clearing lesions located on the lower part of the clivus and CJC. The structural integrity of the occipital condyle must be understood to prevent any damage to the hypoglossal nerve: Kizilkanat et al. (2006) has described the morphometry and variations of the hypoglossal canal and occipital condyle. Furthermore, knowing the distance between OC and FM can facilitate the surgery and prevent nerve injury. In the present study there was a slight but non-significant difference between the left and right OC - FM distances (8.3-9.3 mm). The sphenoid has been used as a reference for evaluating and analyzing asymmetry (Kim et al., 2003). On the other hand, surgeons using the sphenoid as a reference should remember that the cause of asymmetry is the sphenoid (Kizilkanat et al., 2007).

The parameters measured in the current study are similar to those in the literature; however they have not been examined in Anatolian dry skulls before. Ji et al. (2012), while defining the shape of the clivus and the points to which the plate screws could be fixed, Kizilkanat et al. (2006) and Ozer et al. (2011) studied the morphometry and variations of the occipital condyle.

Ji et al. (2012) reported an irregular trapezoid like shape on the clivus by linking the bilateral medial external margin of the hypoglossal canal, foramen lacerum and the apex of the extracranial clivus, which is a safer area for entry points. The distances between bilateral hypoglossal canals and foramen lacerum were observed to be $33.3 \mathrm{~mm}$ and 20.1 $\mathrm{mm}$ respectively in the current study, similar to the values reported by Ji et al. (2012).

The mean distances between PT and FL in the present study (left: $17.1 \mathrm{~mm}$; right: $17.4 \mathrm{~mm}$ ) were greater than those reported by Ji et al. (2012). The internal carotid artery passes over the foramen lacerum, which is considered the lateral border in transsphenoidal and transoral approaches to clivus. Furthermore, the maximum distances between the pharyngeal tubercle and hypoglossal canal were greater on each side than in the study by Ji et al. (2012). The external entrance of hypoglossal canal joins the boundaries of the safe irregular trapezoid, with the XIIth cranial nerve passing through the canal (Kizilkanat et al., 2006).

The findings of various studies have been compared with those in the current study and demonstrate differences and similarities in the distances measured. Existing morphometric data can be helpful not only for surgical procedures in the region, but also for practitioners viewing the skull base and images of the clivus. It also will be helpful in increasing the safety of chordoma resection. The morbidity and mortality rate during the surgical procedures in the region should decrease in light of the data presented in the current study. Neurosurgeons using transoral or transnasal 
endoscopy for neoplasm resection and stabilization of the CJC will also be able to use the data presented in this study. Before final conclusions regarding the precise clinical practice can be determined, the current neurosurgical related measurements require further study. The fragile anatomical structures located in the skull base are vulnerable to surgical manipulations. Having a detailed knowledge of the anatomical structures of this region will help prevent intraoperative damage to neurovascular structures, as well as improve surgical techniques. While many studies have been published based on intraoperative observations, it is concluded that the observations of the present study will help surgeons adopt and follow the most appropriate route during the neurosurgical procedures.

\section{ACKNOWLEDGEMENTS}

Special thanks to Anatomy Department of the Medical Faculty of Cukurova University for supplying valuable anatomical materials to evaulate in the present study.

ERDEM, H.; KIZILKANAT, E. D.; BOYAN, N.; SOAMES, R. \& OGUZ, O. Anatomía e importancia clínica del clivus extracraneal y las estructuras circundantes. Int. J. Morphol., 36 (2):557-562, 2018.

RESUMEN: El objetivo de este estudio fue revelar la importancia clínica de las mediciones tomadas desde el tubérculo faríngeo (TF) a diversas estructuras anatómicas alrededor del clivus extracraneal. Veintiséis cráneos, secos adultos, de Anatolia, fueron examinados. El clivus extracraneal y TF se utilizaron como puntos de referencia a partir de los cuales se midieron varias distancias con un calibrador digital con una precisión de $0,01 \mathrm{~mm}$. Se observaron las siguientes distancias medias del TF: foramen lacerum (FL) (L: $17.15 \mathrm{~mm}$, R: 17,4 mm); margen externo medial del canal carotídeo (CC) (L: 26,7 mm, R: 27,5 mm); parte anterior del cóndilo occipital (OC) (L: 16,4 mm, R: 16,3 mm); margen anterior del foramen magnum (FM) (10,8 mm); foramen oval (FO) (L: 25,9 mm, R: 29,1); margen medial de la fosa yugular (FY) (L: 25,4 mm, R: 25,7 mm); margen medial del canal hipogloso (CH) (L: 20,0 mm, R: 19,9 mm). Las distancias bilaterales medias fueron: LFO-RFO: 45,34 mm; LFLRFL: 20,1 mm; LCC-RCC: 52,1 mm; LOC-ROC: 17,6 mm; LJFRJF: 45,2 mm; LHC-RHC: 33,5 mm. Se observaron las siguientes distancias medias de la FM: FM-OC (L: $8,3 \mathrm{~mm}$, R: 9,3 mm); FMCH (L: 17,8 mm, R: 17,4 mm). También se observó la distancia media de OC-CH (L: 11,7 mm, R: 11,4 mm). Las mediciones actuales sugieren que el TF puede ser utilizado como un hito anatómico durante la cirugía que involucra la patología clival. Sin embargo, se deben tener en cuenta la anatomía y las variaciones del clivus extracraneal y las estructuras circundantes.

PALABRAS CLAVE: Clivus extracraneal; Base media del cráneo; Tubérculo faríngeo; Base del cráneo.

\section{REFERENCES}

Berson, A. M.; Castro, J. R.; Petti, P.; Phillips, T. L.; Gauger, G. E.; Gutin, P.; Collier, J. M.; Henderson, S. D. \& Baken, K. Charged particle irradiation of chordoma and chondrosarcoma of the base of skull and cervical spine: the Lawrence Berkeley Laboratory experience. Int. J. Radiat. Oncol. Biol. Phys., 15(3):559-65, 1988.

Cavallo, L. M.; Cappabianca, P.; Messina, A.; Esposito, F.; Stella, L.; de Divitiis, E. \& Tschabitscher, M. The extended endoscopic endonasal approach to the clivus and cranio-vertebral junction: anatomical study. Childs. Nerv. Syst., 23(6):665-71, 2007.

Choi, D. \& Gleeson, M. Surgery for chordomas of the craniocervical junction: lessons learned. Skull Base, 20(1):41-5, 2010.

Doglietto, F.; Prevedello, D. M.; Jane, J. A. Jr.; Han, J. \& Laws, E. R. Jr. Brief history of endoscopic transsphenoidal surgery--from Philipp Bozzini to the First World Congress of Endoscopic Skull Base Surgery. Neurosurg. Focus, 19(6):E3, 2005.

Erdem, E.; Angtuaco, E. C.; Van Hemert, R.; Park, J. S. \& Al-Mefty, O. Comprehensive review of intracranial chordoma. Radiographics, 23(4):995-1009, 2003.

Gholve, P. A.; Hosalkar, H. S.; Ricchetti, E. T.; Pollock, A. N.; Dormans, J. P. \& Drummond, D. S. Occipitalization of the atlas in children. Morphologic classification, associations, and clinical relevance. J. Bone Joint Surg. Am., 89(3):571-8, 2007.

Jackson, C. G. Skull base surgery. Am. J. Otol., 3(2):161-71, 1981.

Ji, W.; Liu, X.; Huang, W.; Huang, Z.; Chen, J.; Zhu, Q. \& Wu, Z. Clival screw placement in patient with atlas assimilation: A CT-based feasibility study. Sci. Rep., 6:31648, 2016a.

Ji, W.; Tong, J.; Huang, Z.; Zheng, M.; Wu, X.; Chen, J. \& Zhu, Q. A clivus plate fixation for reconstruction of ventral defect of the craniovertebral junction: a novel fixation device for craniovertebral instability. Eur. Spine J., 24(8):1658-65, 2015.

Ji, W.; Tong, J.; Huang, Z.; Zheng, M.; Wu, X.; Chen, J. \& Zhu, Q. Stabilization of the craniovertebral junction with clivus plate constructs: Biomechanical comparison with conventional technique. World Neurosurg., 94:42-9, 2016b.

Ji, W.; Wang, X. Y.; Xu, H. Z.; Yang, X. D.; Chi, Y. L.; Yang, J. S.; Yan, S. F.; Zheng, J. W. \& Chen, Z. X. The anatomic study of clival screw fixation for the craniovertebral region. Eur. Spine J., 21(8):1483-91, 2012.

Jian, B. J.; Bloch, O. G.; Yang, I.; Han, S. J.; Aranda, D. \& Parsa, A. T. A comprehensive analysis of intracranial chordoma and survival: a systematic review. Br. J. Neurosurg., 25(4):446-53, 2011.

Kim, Y. H.; Sato, K.; Mitani, H.; Shimizu, Y. \& Kikuchi, M. Asymmetry of the sphenoid bone and its suitability as a reference for analyzing craniofacial asymmetry. Am. J. Orthod. Dentofacial Orthop., 124(6):656-62, 2003.

Kizilkanat, E. D.; Boyan, N.; Soames, R. \& Oguz, O. Morphometry of the hypoglossal canal, occipital condyle, and foramen magnum. Neurosurg. Q., 16(3):121-5, 2006.

Kizilkanat, E. D.; Boyan, N.; Tekdemir, I.; Soames, R. \& Oguz, O. Surgical importance of the morphometry of the anterior and middle cranial fossae. Neurosurg. Q., 17(1):60-3, 2007.

Kondziolka, D.; Lunsford, L. D. \& Flickinger, J. C. The role of radiosurgery in the management of chordoma and chondrosarcoma of the cranial base. Neurosurgery, 29(1):38-45, 1991.

Liu, J. K.; Das, K.; Weiss, M. H.; Laws, E. R. Jr. \& Couldwell, W. T. The history and evolution of transsphenoidal surgery. J. Neurosurg., 95(6):1083-96, 2001.

Ozer, M. A.; Celik, S.; Govsa, F. \& Ulusoy, M. O. Anatomical determination of a safe entry point for occipital condyle screw using three-dimensional landmarks. Eur. Spine J., 20(9):1510-7, 2011.

Patel, C. R.; Fernandez-Miranda, J. C.; Wang, W. H. \& Wang, E. W. Skull base anatomy. Otolaryngol. Clin. North Am., 49(1):9-20, 2016. 
Sen, C. N.; Sekhar, L. N.; Schramm, V. L. \& Janecka, I. P. Chordoma and chondrosarcoma of the cranial base: an 8-year experience. Neurosurgery, 25(6):931-40, 1989.

Shin, H.; Barrenechea, I. J.; Lesser, J.; Sen, C. \& Perin, N. I. Occipitocervical fusion after resection of craniovertebral junction tumors. J. Neurosurg. Spine, 4(2):137-44, 2006

Solari, D.; Chiaramonte, C.; Di Somma, A.; Dell'Aversana Orabona, G.; de Notaris, M.; Angileri, F. F.; Cavallo, L. M.; Montagnani, S.; Tschabitscher, M. \& Cappabianca, P. Endoscopic anatomy of the skull base explored through the nose. World Neurosurg., 82(6 Suppl.):S16470, 2014.

Stippler, M.; Gardner, P. A.; Snyderman, C. H.; Carrau, R. L.; Prevedello, D. M. \& Kassam, A. B. Endoscopic endonasal approach for clival chordomas. Neurosurgery, 64(2):268-77, 2009.

Wang, A. J.; Zaidi, H. A. \& Laws, E. D. Jr. History of endonasal skull base surgery. J. Neurosurg. Sci., 60(4):441-53, 2016.

Yin, Y. H.; Qiao, G. Y.; Yu, X. G.; Tong, H. Y. \& Zhang, Y. Z. Posterior realignment of irreducible atlantoaxial dislocation with C1-C2 screw and rod system: a technique of direct reduction and fixation. Spine J., 13(12):1864-71, 2013.
Corresponding author:

Prof. Ozkan Oguz, Ph.D

Department of Anatomy

Faculty of Medicine

Cukurova University

01330, Balcali

Adana

TURKEY

Email: ozoguz@cu.edu.tr

Received: 07-10-2017

Accepted: 19-12-2017 